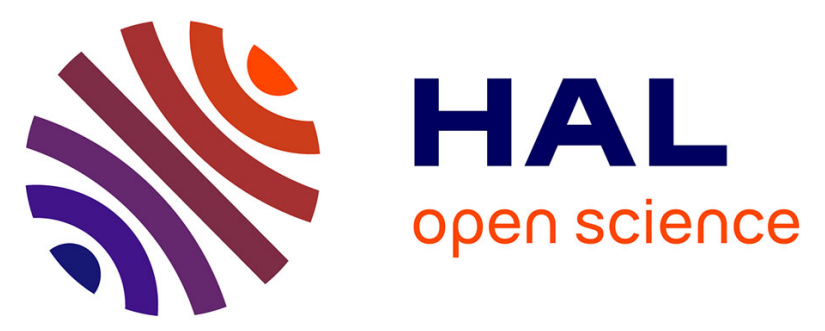

\title{
Parkinson's Disease-Related Impairments in Body Movement, Coordination and Postural Control Mechanisms When Performing 80 Lateral Gaze Shifts.
}

\author{
Cédrick T. Bonnet, Arnaud Delval, Luc Defebvre
}

\section{To cite this version:}

Cédrick T. Bonnet, Arnaud Delval, Luc Defebvre. Parkinson's Disease-Related Impairments in Body Movement, Coordination and Postural Control Mechanisms When Performing $80^{\circ}$ Lateral Gaze Shifts.. IEEE Transactions on Neural Systems and Rehabilitation Engineering, 2015, IEEE transactions on neural systems and rehabilitation engineering a publication of the IEEE Engineering in Medicine and Biology Society, 23, pp.849-856. 10.1109/TNSRE.2014.2369455 . hal-02186231

\section{HAL Id: hal-02186231 \\ https://hal.univ-lille.fr/hal-02186231}

Submitted on 27 May 2021

HAL is a multi-disciplinary open access archive for the deposit and dissemination of scientific research documents, whether they are published or not. The documents may come from teaching and research institutions in France or abroad, or from public or private research centers.
L'archive ouverte pluridisciplinaire HAL, est destinée au dépôt et à la diffusion de documents scientifiques de niveau recherche, publiés ou non, émanant des établissements d'enseignement et de recherche français ou étrangers, des laboratoires publics ou privés. 


\title{
Parkinson's Disease-Related Impairments in Body Movement, Coordination and Postural Control Mechanisms when Performing $80^{\circ}$ Lateral Gaze Shifts
}

\author{
Cédrick T. Bonnet, Arnaud Delval, and Luc Defebvre, Member, IEEE
}

\begin{abstract}
We investigated early signs of Parkinson's diseaserelated impairment in mediolateral postural control. Thirty-six participants (18 Hoehn \& Yahr stage 2 patients in the off-drug condition and 18 healthy controls) were studied in a stationary gaze condition and when performing $80^{\circ}$ lateral gaze shifts at 0.125 $\mathrm{Hz}$ and $0.25 \mathrm{~Hz}$. Body sway, coordination and postural control mechanisms were analyzed. All participants performed the visual tasks adequately. The patients were not unstable in the stationary gaze condition. In both groups, mediolateral ankle- and hip-based postural control mechanisms were significantly more active under gaze shift conditions than under the stationary gaze condition. As expected, the patients exhibited significantly greater angular movements of the lower back and significantly lower angular movements of the head (relative to controls) when performing gaze shifts. When considering linear displacements (rather than angular movements), the patients exhibited significantly greater displacements of the lower back and lower, slower displacements of the head than controls under gaze shift conditions. Relative to controls, the patients performed "en block" body movements. Overall, our results show that the patients' ankle- and hip-based mediolateral postural control mechanisms did not adapt to the difficulty of the visual task being performed.
\end{abstract}

Index Terms-Parkinson's disease, Postural control mechanisms, Postural coordination, Visual tasks, Mediolateral axis

\section{INTRODUCTION}

$\mathrm{T}$ HE classical symptoms of Parkinson's disease (PD, a basal ganglia disorder) include rest tremor, rigidity, slowness of movement and hypokinesia. Patients with PD also display (i) postural instability in both late-stage disease (>Hoehn \& Yahr Stage 2.5 [1]) and early-stage disease [2], [3], and (ii) disease-related reductions in the contribution of postural control mechanisms. However, the latter changes have not been fully characterized.

Some literature data suggest the presence of early-onset impairments in mediolateral (ML) postural control in PD. Patients with PD exhibit more ample ML body displacements

Manuscript received January 29, 2014 ; accepted September 15, 2014

C. T. Bonnet, A. Delval and L. Defebvre are members of the Laboratoire de Neurosciences Fonctionnelles et Pathologies, Université Lille, France (e-mail: cedrick.bonnet@ chru-lille.fr; tel.: +33 320446 281; fax: +33 320446 732). than healthy controls [4]-[6]. It is known that ML postural control worsens as PD progresses [6], [7]. Patients with PD exhibit more ample and/or slower ML trunk displacements in quiet stance [1], [8]-[10], during unexpected platform motions [11] and when performing multiple tasks [8]. Patients with PD also present disease-related impairments in body rotation around the trunk axis [12]. This ML postural instability is problematic because it can lead to ML falls [13], which in turn are directly related to the incidence of hip fractures [14]. In order to prevent ML falls in patients with $\mathrm{PD}$, postural instability has to be detected early in the course of the disease. In the present manuscript and for the sack of clarity, the terms "movement" and "displacement" respectively refer to taskrelated angular body motion and the magnitude of linear body oscillation (although this is not conventional).

Researchers have identified two ML postural control mechanisms: a bodyweight distribution mechanism (referred to as "loading/unloading contribution to vertical forces") and a center of pressure (COP) location mechanism (referred to as "left and right COP change" [15], [16]). The two mechanisms are complementary and account for different proportions of the COP displacement. To the best of our knowledge, only [17] have analyzed PD-related impairments in these two ML postural control mechanisms. In their study, [17] studied two groups of participants (young, healthy controls and patients with PD) under three conditions: a quiet stance condition (with the feet parallel and side-by-side at pelvis width), a $45^{\circ}$ (diagonal) quiet stance condition (with the feet parallel at pelvis width but with the right foot placed forward of the left foot by $80 \%$ of the foot length) and a stooped posture (with the feet side-by-side and the trunk and knees flexed; see Fig. 1C in [17]). The researchers did not find any disease-related impairment in bodyweight distribution or COP location mechanisms in either quiet stance or the $45^{\circ}$ condition. However, in the stooped posture condition, patients with PD had a significantly lower amplitude contribution of the ML bodyweight distribution mechanism than controls. However, the patients did not need to activate the ML bodyweight distribution mechanism as intensely as controls because the

A. Delval is also a member of the Service de Neurophysiologie Clinique, Hôpital Salengro, CHRU, Lille, France.

L. Defebvre is also a member of the Service de Neurologie et Pathologie du Mouvement, Hôpital Salengro, CHRU, Lille, France 
patients exhibited significantly lower COP and center of mass (COM) displacements. Indeed, this contrasted with the classical signs of postural instability, i.e. greater COP and/or COM displacements. However, [17] did not challenge the participants' ML postural control and thus were less likely to detect disease-related impairments in the corresponding control mechanisms.

Mediolateral postural control can be challenged by the performance of active tasks that repeatedly cause the body to move laterally (i.e. leftwards and rightwards). For example, shifting the gaze leftwards and rightwards (e.g. when tracking a visual target) is known to increase ML COP displacement in young adults [18]. This kind of perturbation has also been applied to patients with PD. In their study, [19] invited patients and controls to perform active lateral gaze shifts of $45^{\circ}, 90^{\circ}$ or $135^{\circ}$ to the left and to the right. Patients with PD were found to exhibit more ample ocular movement than controls - probably in order to compensate for smaller head and trunk movements as part of an "eye-dominant strategy" [19]). Nevertheless, patients with PD performed the task successfully and exhibited much the same degree of eye-foot coordination as healthy controls [19].

The primary objective of the present study was to detect Parkinson's disease-related impairments in ML postural movement and assess the relationships between these impairments on one hand and postural coordination and control mechanisms on the other. In two groups (i.e. patients with PD and healthy controls), ML postural control was challenged by the performance of ML gaze shifts (visual angle: $80^{\circ}$ ) at 0.125 $\mathrm{Hz}$ and $0.25 \mathrm{~Hz}$. We selected patients in the early stages of the disease (Hoehn \& Yahr stage 2), in order to study impairments in ML postural control that might have occurred before a clinical diagnosis of postural instability. We chose to use a moderately difficult visual task, so as to avoid excessively large between-subject variability and reduce the risk of falls. Nevertheless, these visual tasks were expected to increase ML body displacements of the lower back and neck and therefore increase (at least in controls) the contributions of bodyweight distribution and COP location mechanisms to overall ML postural control. Hence, we expected to find PD-related impairments in ML postural control, coordination and mechanisms during active gaze shifting but not in quiet stance [17]. Under active conditions, we expected to see an abnormally small increase in bodyweight distribution and COP location mechanisms in patients, as a sign of impairment at the trunk [19], [20] and at the ankles [21]. We assumed that the greater the difficulty of the visual task, the greater the intergroup differences in ML postural displacement, coordination and control mechanisms would be.

\section{MetJHOdS}

\section{A. Participants}

\section{1) Inclusion/Exclusion Criteria}

Patients with PD were invited to participate in the study during consultations at the Neurology Department at Lille University Medical Center (Lille, France). Patients were included if their Hoehn \& Yahr stage score was below 2.5 [22].
Hence, these patients had mild, bilateral disease but no clinically visible impairments in postural control. The patients performed the tasks under "off-drug" conditions, in order to remove potential bias due to the effects of antiparkinsonian medications on postural behavior [23]. The participants were included if they (i) had good or corrected visual acuity and (ii) scored more than 25 in the Mini-Mental State Examination [24]. The patients were instructed not to take their medications in the $12 \mathrm{~h}$ prior to the experiment. Hence, the experiment was performed in the morning (for both patients and controls).

Participants were excluded if they had any neurological diseases (except for PD in the patient group), musculoskeletal or vestibular diseases or recurrent dizziness or if they were taking any medications that might have affected their posture. Participants were also excluded if they presented signs of dementia or had known hip- and ankle-related diseases or injuries.

\section{2) Characteristics of the Participants}

Eighteen patients with PD (twelve males and six females) were included in the study. The group's mean \pm standard deviation (SD) age, bodyweight and height were $60.4 \pm 8.11$ years, $78.6 \pm 12.7 \mathrm{~kg}$ and $1.71 \pm 0.07 \mathrm{~m}$, respectively. Eighteen controls (twelve males and six females) also participated; the mean age, bodyweight and height were $61.6 \pm 5.7$ years, $77.9 \pm$ $18.7 \mathrm{~kg}$ and $1.69 \pm 0.09 \mathrm{~m}$, respectively. There were no intergroup differences in terms of age, weight or height $(p>0.42)$. None of the participants had fallen in the previous six months.

All patients were diagnosed according to the United Kingdom Parkinson's Disease Brain Bank criteria [25]. The mean time since disease onset was $3.9 \pm 2.3$ years. None of the patients presented motor fluctuations or dyskinesia. All patients were Hoehn \& Yahr stage 2 [22]. The mean motor Unified Parkinson's Disease Rating Scale (UPDRS) score (part III) in the off-drug condition was $16.22 \pm 6.89$. The patients had a mean axial score of $3.94 \pm 2.31$ (calculated by summing UPDRS III items 18, 22, 27, 28, 29, and 30 [26]) and a mean postural stability score of $1.28 \pm 1.02$ (calculated by summing UPDRS III items 18, 27, 28, 29, and 30 [27]). The patients were receiving a mean daily total levodopa equivalent dose of $420 \pm$ $168 \mathrm{mg}$.

The study's objectives and protocols were approved by the local investigational review board (reference: 11/25) and all the patients and controls gave their written, informed consent to participation.

\section{B. Apparatus}

A black dot (visual angle: $5^{\circ}$ ) was projected onto a panoramic display (radius: $2.1 \mathrm{~m}$; height: $2.1 \mathrm{~m}$; Fig. 1) at three positions at the participant's eye height: in front, to the left and to the right.

Loading/unloading of body weight under each foot (i.e. the bodyweight distribution mechanism) cannot be measured with a single force platform [15], so we used a dual-top force platform (AMTI, Watertown, MA) with a sampling frequency of $120 \mathrm{~Hz}$. Participants stood barefoot on the force platform.

A two-camera video motion analysis system (version 7.5, SIMI Reality Motion Systems GmbH, Munich) was used to record the motions of reflective markers, with a sampling 
frequency of $15 \mathrm{~Hz}$. The reflective markers were attached to the back of a hip belt (the lower back marker), the back of the neck (the neck marker) and the back of a headset (the head marker; Fig. 1). Special lights mounted on each of the two cameras (LED Lenser P3 8403, LED Nichia) were used to illuminate the markers.

A head-mounted eye-tracker (SensoMotoric Instruments, Teltow) was attached to a headset worn by the participant. The iViewX system recorded the pupil position at a sampling rate of $50 \mathrm{~Hz}$. The system's video showed the visual environment and (as a cross) what the right eye was looking. The various items of equipment were synchronized with one another.

\section{Conditions, Instructions and Procedure}

The participants performed trials under three conditions. For the purposes of randomization, each patient was paired with a control and the order in which the conditions were performed was randomly assigned to both participants. Each condition was repeated four times and each trial lasted $32 \mathrm{~s}$. In the stationary gaze condition, the participants stared at a black dot in front of them. They stood in a relaxed position but were instructed to refrain from making any voluntary movements. In the gaze shift conditions, the participants had to track a dot that appeared alternately on their left and their right at a visual angle of $80^{\circ}$ (Fig. 1) and at $0.125 \mathrm{~Hz}$ or $0.25 \mathrm{~Hz}$. Gaze shifts had to be performed as soon as the target had completely disappeared [18]. In each condition, the participant's goal was to keep his/her eyes on the target for as long as possible while maintaining a relaxed stance. The participants were instructed to move as naturally as possible in the gaze shift conditions. The participants were also told that they had to look at the target through the eye-tracker's small window $\left(20^{\circ}\right.$ on each side); eye movement outside this range was not recorded. Hence, the participants were told that they had to shift their gaze quickly (by about $80^{\circ}$ ) in the manner that they found most comfortable (i.e. by turning the head but not the trunk, turning the trunk only or turning both the head and the trunk together to some extent). No particular type of movement was recommended. It is important to note that for the purposes of the present report, the term "lower back" refers to the lower back marker and 'trunk' refers to the whole back (i.e. from the neck to the lower back marker). We analyzed the linear displacements of the markers and the angular displacements of the head and trunk vectors relative to the YZ plane.
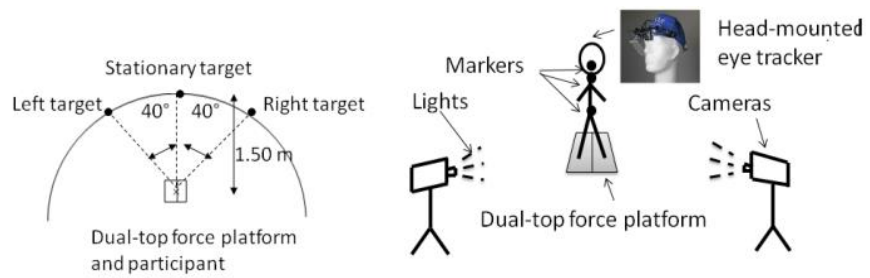

Fig. 1. Description of the experimental setting. In the left panel, the cross represents the participant who stood on a dual-top force platform placed 1.50 $\mathrm{m}$ away from a semicircular, panoramic display. The target (a black dot, subtending a visual angle of $5^{\circ}$ ) was presented either in a stationary position in front of the participant or alternately on the left and right at a visual angle of $80^{\circ}$. The right panel shows the head mounted eye tracker, the markers, the platform and the SIMI motion analysis system's two cameras.

The participant's foot position was standardized, with a stance width of $14 \mathrm{~cm}$ and a stance angle of $17^{\circ}$ [28]. During the 0.125 and $0.25 \mathrm{~Hz}$ trials, the experimenter checked (on the eye-tracker video) that the participants reached every single visual target. As is usually the case with young adults [18], there was never any need to repeat a trial and all participants were able to track the target at the requested amplitude and frequency and at the right moment.

\section{Dependent Variables}

The mean, $\mathrm{SD}$, range and mean velocity values were used to analyze $\mathrm{COP}$ and body marker position and displacement.

To calculate the contributions of the bodyweight distribution and COP location mechanisms, we used an updated version [29], [30] of the validated model of ML postural control [15][17], [31]. First, we used three equations to calculate three time series: (1) the resultant COP displacement $\left(\mathrm{COP}_{\text {net }}\right)$, (2) the COP displacement explained by the COP location mechanism (denoted as $\mathrm{COP}_{c}$ in the model calculation, where $c$ stands for "changes") and (3) the COP displacement explained by the bodyweight distribution mechanism (denoted as $\mathrm{COP}_{v}$ in the model calculation, where $v$ stands for "vertical"):

$$
\begin{aligned}
& \operatorname{COP}_{n e t}(t)=\operatorname{COP}_{l}(t) \frac{R_{v l}(t)}{R_{v l}(t)+R_{v r}(t)}+\operatorname{COP}_{r}(t) \frac{R_{v r}(t)}{R_{v l}(t)+R_{v r}(t)} \\
& \operatorname{COP}_{c}(t)=C O P_{l}(t) \times m e a n R_{v l}+C O P_{r}(t) \times m e a n R_{v r} \\
& \operatorname{COP}_{v}(t)=\operatorname{meanCOP} \frac{R_{v l}(t)}{R_{v l}(t)+R_{v r}(t)}+\operatorname{meanCOP}_{r} \frac{R_{v r}(t)}{R_{v l}(t)+R_{v r}(t)}
\end{aligned}
$$

$\mathrm{COP}_{l}(\mathrm{t})$ and $\mathrm{COP}_{r}(\mathrm{t})$ are the COP displacements under the left and right feet, respectively. $\mathrm{R}_{v l}(\mathrm{t})$ and $\mathrm{R}_{v r}(\mathrm{t})$ are the vertical reaction forces under the left and right feet, respectively. $\mathrm{MeanCOP}_{l}$, meanCOP$r$, meanR $\mathrm{R}_{v l}$ and meanR $\mathrm{R}_{v r}$ are the means of each respective time series.

Equation (1) simply shows how the COP displacement (or $\mathrm{COP}_{\text {net }}$ ) was computed with two force platforms [16]. In equation (2), the $\mathrm{COP}_{c}$ displacement was calculated by eliminating the $\mathrm{COP}_{\text {net }}$ displacement explained by the $\mathrm{COP}_{v}$ displacement (given that the mean body weight measured under the two feet was constant throughout the trial). In equation (3), the $\mathrm{COP}_{v}$ displacement was calculated by eliminating the $\mathrm{COP}_{\text {net }}$ displacement explained by the $\mathrm{COP}_{c}$ displacement (given that the mean center of pressure location measured under the two feet was constant throughout the trial). Fig. 2 shows the results of these equations for one representative trial.

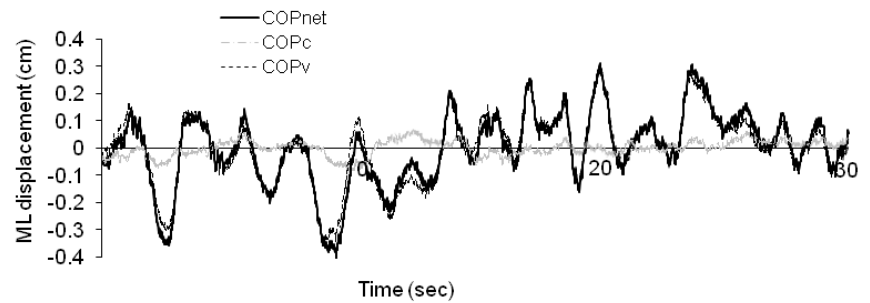

Fig. 2. Mediolateral (ML) time series for $\mathrm{COP}_{\text {net }}, \mathrm{COP}_{v}$ and $\mathrm{COP}_{c}$ in a single, 30 -second long trial performed by the experimenter (units: $\mathrm{cm}$ ). The $\mathrm{COP}_{\text {net }}$ is the integrated displacement of the center of pressure (COP) under the two feet. $\mathrm{COP}$ vertical $\left(\mathrm{COP}_{v}\right)$ is the component of the $\mathrm{COP}_{\text {net }}$ that can be explained by the bodyweight distribution mechanism. The COP change $\left(\mathrm{COP}_{c}\right)$ is the component of the $\mathrm{COP}_{\text {net }}$ that can be explained by the COP location mechanism. 
Once the three time series were obtained, two additional analyses were performed in order to assess the contribution of each mechanism. The first analysis compared the amplitudes of $\mathrm{COP}_{\text {net }}$ and $\mathrm{COP}_{c}$ time series and the $\mathrm{COP}_{\text {net }}$ and $\mathrm{COP}_{v}$ time series, in order to compute the amplitude of each mechanism's contribution. This was done by analyzing the $\mathrm{SD}$ of $\mathrm{COP}_{c}$, $\mathrm{COP}_{v}$ and $\mathrm{COP}_{\text {net }}$ [29], [30]. The relative amplitude corresponds to the extent to which the variability of $\mathrm{COP}_{\text {net }}$ was explained by one or other of the mechanisms (SD COP $/$ SD COP ${ }_{\text {net }}$ and $\mathrm{SD} \mathrm{COP}_{v} / \mathrm{SD} \mathrm{COP}{ }_{\text {net }}$ ). The absolute amplitude corresponds to SD COP ${ }_{c}$ and SD COP ${ }_{v}$, irrespective of SD COP ${ }_{\text {net }}$ [29],[30]. Hence, we differentiated between the relative amplitude contribution and the absolute amplitude contribution in subsequent analyses.

The second analysis looked at cross-correlations (with no lag) for $\mathrm{COP}_{v}$ vs. $\mathrm{COP}_{\text {net }}$ and for $\mathrm{COP}_{c}$ vs. $\mathrm{COP}_{\text {net }}$ [15]-[17], [29]-[31]. As in our earlier study [32], we assumed that the degree of similarity between $\mathrm{COP}_{c}$ and $\mathrm{COP}_{v}$ (both in terms of direction and the proportionality of the time series) on one hand and $\mathrm{COP}_{\text {net }}$ on the other might indicate the extent to which each mechanism actively contributes to the control of $\mathrm{COP}_{\text {net }}$. Indeed, cross-correlation analyses are not influenced by the amplitude of the signals and thus are not relevant when considering the amplitude of each mechanism's contribution. We assumed that the higher the cross-correlation coefficient, the higher the postural mechanism's active contribution to the control of ML COP displacement.

The eye-in-orbit angular displacement corresponds to the angle formed by the eye relative to the orbit. This angle was obtained by measuring the ML linear displacements of the eye and applying an inverted tangent function (angle $=a \tan (\mathrm{ML}$ linear displacement of the eye/distance of the participant from the display)). Given that the panoramic display was curved (rather than linear), this angle was slightly underestimated. However, the eye-in-orbit angular displacements recorded were so small that the error was $0.01^{\circ}$ at most. The head-in-space and trunk-in-space angular displacements corresponded to the planar yaw angles of the head-neck vector and the neck-lower back vector projected on the horizontal plane, respectively. These angular displacements were obtained directly from the SIMI Reality Motion System software. Since the system recorded data relative to the earth reference, the head-on-trunk angular displacement was obtained by subtracting the trunk-in-space angular displacement from the head-in-space angular displacement.

The mean angular position of the eyes and head when viewing the right and left targets were calculated (with two means and four means per time series in the $0.125 \mathrm{~Hz}$ and 0.25 $\mathrm{Hz}$ conditions, respectively). The resulting mean left and right angles were averaged for each trial. The mean left and right angular positions of the trunk were calculated at the same time point as the mean left and right angular positions of the head (i.e. the two time series in the $0.125 \mathrm{~Hz}$ and the four time series in the $0.25 \mathrm{~Hz}$ condition had the same start time and the same end time) in both gaze shift conditions. We did this because the time-series for trunk-in-space angular displacement were not usually related to the target position (i.e. the trunk-in-space angular displacement time-series was pseudorandom).

\section{E. Data Analysis}

The data were not filtered. All the dependent variables (COP displacement, body movement, amplitude and active contributions of the bodyweight distribution and COP location mechanisms, and eye-in-orbit angular movement) were analyzed in the ML axis. Preliminary analyses had shown that the datasets for neck displacement, lower back displacement, active contribution and relative amplitude contribution were normally distributed and did not present any outlying data points. However, the other dependent variables presented outliers. Hence, a two-way, repeated-measures analysis of variance (ANOVA: group, visual condition), a Friedman ANOVA and the Mann-Whitney $U$ test were used as appropriate. In all these analyses, the threshold for statistical significance was set to $p<0.05$. Spearman rank correlations were calculated for the relationships between clinical scores (mean UPDRS III score, axial UPDRS III score, postural stability UPDRS III score) and all dependent postural variables under the three visual conditions ( $p$-value $<0.025$, with Bonferroni correction for multiple comparisons).

\section{RESUILTS}

\section{A. Main Effects of Group on All the Dependent Variables}

\section{1) In Non-Parametric Analyses}

The results of the Mann-Whitney $U$ tests showed that in the two gaze shift conditions, patients with PD exhibited a significantly lower rank of head displacement for the range, SD, and mean velocity than controls $\operatorname{did}\left(U_{s}<88.00, p<0.05\right.$; Fig. 3$)$.
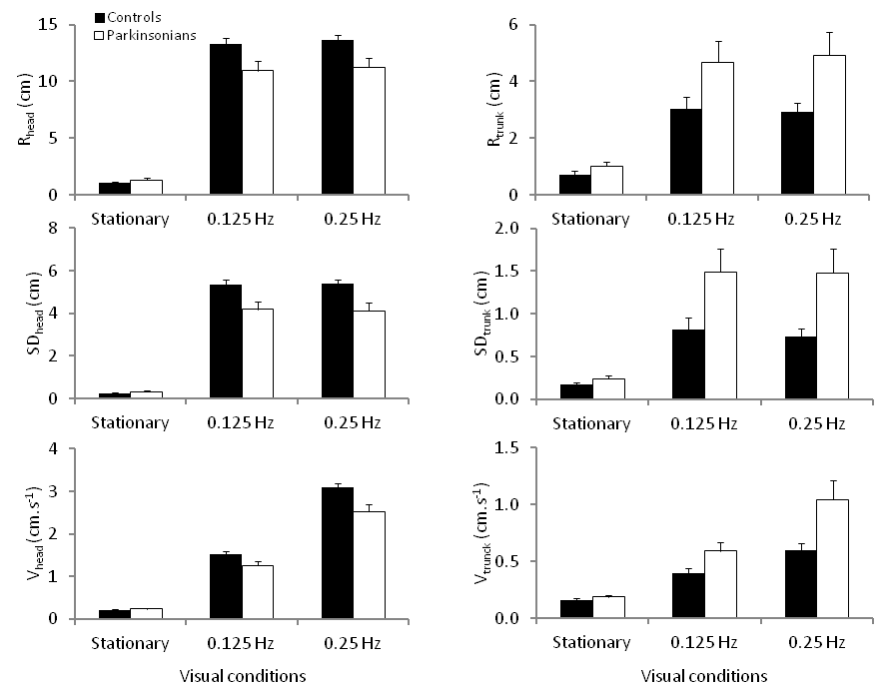

Fig. 3. Significant main effects of group in the Mann-Whitney $U$ tests for ranking the range (R), standard deviation (SD) and mean velocity $(\mathrm{V})$ of the head displacement (left-hand graphs). Significant main effects of group and significant effects of the group $\mathrm{x}$ interaction in the ANOVA for $\mathrm{R}, \mathrm{SD}$ and $\mathrm{V}$ of lower back displacement (right graphs). In the stationary gaze visual condition, participants stared at a black dot in front of them. In the $0.125 \mathrm{~Hz}$ and $0.25 \mathrm{~Hz}$ visual conditions, participants had to track a dot that appeared alternately to their left and right at a visual angle of $80^{\circ}$ at $0.125 \mathrm{~Hz}$ or 0.25 $\mathrm{Hz}$. $\mathrm{R}_{\text {head }}$ and $\mathrm{SD}_{\text {head }}$ are displayed in centimeters $(\mathrm{cm})$ and $\mathrm{V}_{\text {head }}$ is displayed in centimeters per second $\left(\mathrm{cm} \cdot \mathrm{s}^{-1}\right)$. The error bars represent the standard error of the mean. The threshold for statistical significance was set to $p<0.05$.

As an average across the two gaze shift conditions, eyes-inspace, head-on-trunk, and trunk-in-space movements 
accounted respectively for 5\%,53\%, and $42 \%$ of the total movement for patients with $\mathrm{PD}$ (where $100 \%$ is equivalent to $80^{\circ}$ ), whereas controls moved by $4 \%, 73 \%$, and $23 \%$, respectively. The results of the Mann-Whitney $U$ tests showed that the rank of eyes-in-orbit angular movement was greater in patients than in controls in both the $0.25 \mathrm{~Hz}$ condition $\left(3.96^{\circ} \pm 1.51\right.$ vs. $\left.3.03^{\circ} \pm 0.78\right)$ and the stationary gaze condition $\left(0.77^{\circ} \pm 0.69\right.$ vs. $\left.0.44^{\circ} \pm 0.39\right)$. The eyes-in-space angular movements were small in both groups because the participants were instructed to look through the eye tracker's narrow window. The rank of trunk-in-space angular movement was greater in patients than in controls in the two gaze shift conditions $\left(34.06^{\circ} \pm 20.18\right.$ vs. $18.66^{\circ} \pm 17.43$, respectively) and in the stationary gaze condition $\left(0.08^{\circ} \pm 0.07\right.$ vs. $0.05^{\circ} \pm 0.10$, respectively). However, the rank of head-on-trunk angular movement was lower in patients than in controls when considering the average value for the two gaze shift conditions $\left(42.15^{\circ} \pm 19.67\right.$ vs. $58.27^{\circ} \pm 17.31$, respectively).

\section{2) In Parametric Analyses}

Patients with PD exhibited significantly higher range, SD and mean velocity values for lower back displacement $\left(F_{s}>4.70, n_{p}^{2}>0.11, p<0.05\right.$; Fig. 3). Furthermore, the effects of the group $\mathrm{x}$ condition interaction were significant $\left(F_{s}>3.16, n_{p}^{2}\right.$ $>0.08, p<0.05$; Fig. 3). Neck displacement did not have a significant effect $(\mathrm{p}=n s)$.

There were significant effects of the group $\mathrm{x}$ condition interaction for $\mathrm{COP}_{v}$ vs. $\mathrm{COP}_{\text {net }}\left(F(2,68)=3.63, n_{p}^{2}=0.09\right.$, $p<0.05$; Fig. 4) and for $\% \mathrm{SD} \mathrm{COP} / \mathrm{COP}_{\text {net }}\left(F(2,68)=3.80, n_{p}^{2}\right.$ $=0.09, p<0.05$; Fig. 4). No main effects were statistically significant.
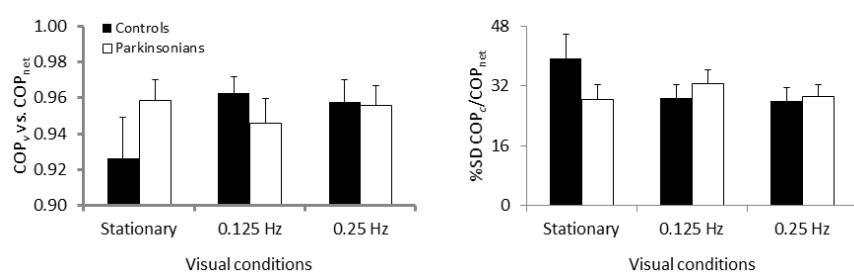

Fig. 4. Significant effects of the group $\mathrm{x}$ interaction (as revealed by an ANOVA) for $\mathrm{COP}_{v}$ vs. $\mathrm{COP}_{\text {net }}$ and $\% \mathrm{SD} \mathrm{COP} / \mathrm{COP}_{\text {net. }}$. The left-hand graph represents the cross-correlation coefficient for the relationship between $\mathrm{COP}_{v}$ and $\mathrm{COP}_{\text {net }}$ in each of the three visual conditions. The right-hand graph represents the amplitude of $\mathrm{COP}_{c}$ as a percentage of the amplitude of $\mathrm{COP}_{\text {net }}$ under the three visual conditions. Definitions of the terms and conditions are given in Figures 2 and 3. The error bars represent the standard error of the mean. The threshold for statistical significance was set to $p<0.05$.

\section{B. Spearman Correlations Between Clinical Scores and Postural Dependent Variables}

None of the correlation coefficients reached statistical significance $\left(r_{s}<0.47\right)$.

\section{Main Effects of Condition on all the Dependent Variables}

The results of parametric and non-parametric ANOVAs show that the gaze shift conditions were more challenging than
TABLE I

\begin{tabular}{|c|c|c|c|c|}
\hline & $0.25 \mathrm{~Hz}$ & $0.125 \mathrm{~Hz}$ & $\begin{array}{c}\text { STATIO } \\
\text { NARY }\end{array}$ & ANOVA \\
\hline $\begin{array}{c}\text { R OF COP } \\
\text { DISPLACEMENT } \\
\text { (CM) }\end{array}$ & $\begin{array}{c}2.62 \\
( \pm 2.05)\end{array}$ & $\begin{array}{c}2.38( \pm 1.5 \\
7)\end{array}$ & $\begin{array}{c}0.92( \pm \\
0.49)\end{array}$ & $X^{2}=42.39, P<0.05$ \\
\hline $\begin{array}{c}\text { SD OF COP } \\
\text { DISPLACEMENT } \\
(\mathrm{CM}) \\
\end{array}$ & $\begin{array}{c}0.59 \\
( \pm 0.55)\end{array}$ & $\begin{array}{c}0.56( \pm 0.4 \\
7)\end{array}$ & $\begin{array}{c}0.19( \pm \\
0.11)\end{array}$ & $X^{2}=41.72, P<0.05$ \\
\hline $\begin{array}{c}\text { V OF COP } \\
\text { DISPLACEMENT } \\
\left(\text { CM.S }^{-1}\right)\end{array}$ & $\begin{array}{c}1.63 \\
( \pm 0.54)\end{array}$ & $\begin{array}{c}1.43( \pm 0.3 \\
0)\end{array}$ & $\begin{array}{c}1.26( \pm \\
0.26)\end{array}$ & $X^{2}=50.00, P<0.05$ \\
\hline $\begin{array}{c}\text { R OF HEAD } \\
\text { DISPLACEMENT } \\
\text { (CM); BETWEEN } \\
\text { THE GAZE SHIFT } \\
\text { CONDITIONS } \\
\end{array}$ & $\begin{array}{c}12.51 \\
( \pm 3.06)\end{array}$ & $\begin{array}{c}12.15( \pm 3 . \\
08)\end{array}$ & & $X^{2}=4.00, P<0.05$ \\
\hline $\begin{array}{c}\text { SD OF HEAD } \\
\text { DISPLACEMENT } \\
\text { (CM); BETWEEN } \\
\text { THE GAZE SHIFT } \\
\text { CONDITIONS } \\
\end{array}$ & $\begin{array}{c}4.79 \\
( \pm 1.43)\end{array}$ & $\begin{array}{c}4.78( \pm 1.4 \\
1)\end{array}$ & & $X^{2}=2.78, P>0.05$ \\
\hline $\begin{array}{c}\text { R OF NECK } \\
\text { DISPLACEMENT } \\
\text { (CM) }\end{array}$ & $\begin{array}{c}4.65 \\
( \pm 2.18)\end{array}$ & $\begin{array}{c}4.46( \pm 2.2 \\
2)\end{array}$ & $\begin{array}{c}1.10( \pm \\
0.57)\end{array}$ & $\begin{array}{c}F(2,68)=88.89, \\
n_{p}^{2}=0.42, P<0.05\end{array}$ \\
\hline $\begin{array}{c}\text { SD OF NECK } \\
\text { DISPLACEMENT } \\
\text { (CM) } \\
\end{array}$ & $\begin{array}{c}1.27 \\
( \pm 0.77)\end{array}$ & $\begin{array}{c}1.29( \pm 0.8 \\
0)\end{array}$ & $\begin{array}{c}0.26( \pm \\
0.14)\end{array}$ & $\begin{array}{c}F(2,68)=57.74, \\
n_{p}^{2}=0.39, P<0.05\end{array}$ \\
\hline $\begin{array}{c}\text { V OF NECK } \\
\text { DISPLACEMENT } \\
\left(\text { CM.S }^{-1}\right) \\
\end{array}$ & $\begin{array}{c}0.98 \\
( \pm 0.44)\end{array}$ & $\begin{array}{c}0.60( \pm 0.2 \\
2)\end{array}$ & $\begin{array}{c}0.22( \pm \\
0.08)\end{array}$ & $\begin{array}{l}F(2,68)=104.66, \\
n_{p}^{2}=0.43, P<0.05\end{array}$ \\
\hline $\begin{array}{l}\text { R OF TRUNK } \\
\text { DISPLACEMENT } \\
\text { (CM) }\end{array}$ & $\begin{array}{c}3.93 \\
( \pm 2.81)\end{array}$ & $\begin{array}{c}3.82( \pm 2.6 \\
0)\end{array}$ & $\begin{array}{c}0.86( \pm \\
0.50)\end{array}$ & $\begin{array}{c}F(2,68)=48.74, \\
n_{p}^{2}=0.37, P<0.05\end{array}$ \\
\hline $\begin{array}{l}\text { SD OF TRUNK } \\
\text { DISPLACEMENT } \\
\text { (CM) }\end{array}$ & $\begin{array}{c}1.10 \\
( \pm 0.99)\end{array}$ & $\begin{array}{c}1.14( \pm 0.9 \\
5)\end{array}$ & $\begin{array}{c}0.20( \pm \\
0.12)\end{array}$ & $\begin{array}{c}F(2,68)=34.90, \\
n_{p}^{2}=0.34, P<0.05\end{array}$ \\
\hline $\begin{array}{c}\text { V OF TRUNK } \\
\text { DISPLACEMENT } \\
\left(\mathrm{CM}^{-1} \mathrm{~S}^{-1}\right)\end{array}$ & $\begin{array}{c}0.82 \\
( \pm 0.59)\end{array}$ & $\begin{array}{c}0.49( \pm 0.2 \\
6)\end{array}$ & $\begin{array}{c}0.18( \pm \\
0.05)\end{array}$ & $\begin{array}{c}F(2,68)=46.68, \\
n_{p}^{2}=0.37, P<0.05\end{array}$ \\
\hline$S D C O P_{V}$ & $\begin{array}{c}0.55 \\
( \pm 0.44)\end{array}$ & $\begin{array}{c}0.51( \pm 0.3 \\
7)\end{array}$ & $\begin{array}{c}0.19( \pm \\
0.10)\end{array}$ & $X^{2}=35.72, P<0.05$ \\
\hline$S D C O P_{C}$ & $\begin{array}{c}0.16 \\
( \pm 0.15) \\
\end{array}$ & $\begin{array}{c}0.16( \pm 0.1 \\
4)\end{array}$ & $\begin{array}{c}0.05( \pm \\
0.03) \\
\end{array}$ & $X^{2}=38.89, P<0.05$ \\
\hline $\begin{array}{c}\% S D \\
C O P_{V} / C O P_{N E T}\end{array}$ & $\begin{array}{c}97.01 \\
( \pm 12.23)\end{array}$ & $\begin{array}{c}95.47( \pm 1 \\
3.81)\end{array}$ & $\begin{array}{c}104.96 \\
( \pm 15.2 \\
5) \\
\end{array}$ & $\begin{array}{c}F(2,68)=6.77, n_{p}^{2} \\
\quad=0.14, P<0.05\end{array}$ \\
\hline $\begin{array}{c}\% S D \\
C^{\prime} O P_{d} / C O P_{N E T}\end{array}$ & $\begin{array}{c}28.80 \\
( \pm 13.93)\end{array}$ & $\begin{array}{c}30.95( \pm 1 \\
3.31)\end{array}$ & $\begin{array}{c}33.90( \\
\pm 19.02 \\
\quad) \\
\end{array}$ & $\begin{array}{c}F(2,68)=1.41, \\
P>0.05\end{array}$ \\
\hline $\begin{array}{c}C O P_{V} V S . \\
C O P_{N E T} \\
\end{array}$ & $\begin{array}{c}0.96( \pm 0.0 \\
4)\end{array}$ & $\begin{array}{c}0.95( \pm 0.0 \\
4) \\
\end{array}$ & $\begin{array}{c}0.94( \pm \\
0.06) \\
\end{array}$ & $\begin{array}{c}F(2,68)=1.07 \\
P>0.05\end{array}$ \\
\hline $\begin{array}{l}C O P_{C} V S . \\
C O P_{N E T}\end{array}$ & $\begin{array}{c}0.27( \pm 0.3 \\
5)\end{array}$ & $\begin{array}{c}0.31( \pm 0.3 \\
7)\end{array}$ & $\begin{array}{c}0.12( \pm \\
0.32)\end{array}$ & $\begin{array}{c}F(2,68)=3.86, n_{p}^{2} \\
\quad=0.09, P<0.05\end{array}$ \\
\hline EYES-IN-SPACE & $\begin{array}{c}3.50 \\
( \pm 1.28)\end{array}$ & $\begin{array}{c}3.32 \\
( \pm 1.42) \\
\end{array}$ & $\begin{array}{c}0.61 \\
( \pm 0.58)\end{array}$ & $X^{2}=55.39, P<0.05$ \\
\hline $\begin{array}{c}\text { HEAD-ON- } \\
\text { TRUNK } \\
\end{array}$ & $\begin{array}{c}49.74 \\
( \pm 20.53) \\
\end{array}$ & $\begin{array}{c}50.68 \\
( \pm 19.84) \\
\end{array}$ & $\begin{array}{c}0.34 \\
( \pm 1.55) \\
\end{array}$ & $X^{2}=54.89, P<0.05$ \\
\hline $\begin{array}{c}\text { TRUNK-IN- } \\
\text { SPACE }\end{array}$ & $\begin{array}{c}26.72 \\
( \pm 20.51) \\
\end{array}$ & $\begin{array}{c}26.00 \\
( \pm 20.13) \\
\end{array}$ & $\begin{array}{c}0.06 \\
( \pm 0.09) \\
\end{array}$ & $X^{2}=54.50, P<0.05$ \\
\hline
\end{tabular}

TABLE 1. RESULTS OF THE ANOVA (REPEATED-MEASURES OR FRIEDMAN), SHOWING THE RANGE (R), STANDARD DEVIATION (SD) AND MEAN VELOCITY (V) OF CENTER OF PRESSURE (COP) AND BODY MARKER (HEAD, NECK, LOWER BACK) DISPLACEMENTS. SD AMPLITUDES OF THE COP (COP VERTICAL) AND COP $_{C}$ (COP CHANGE) WERE EITHER CALCULATED INDIVIDUALLY OR EXPRESSED AS A

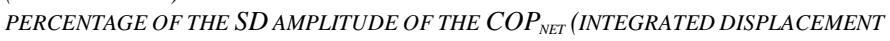
OF THE COP UNDER BOTH FEET). CROSS-CORRELATION COEFFICIENTS FROM TWO ANALYSES: COP V VS. COP ${ }_{N E T}$ AND COP $C$ VS. COP $P_{N E T}$. THE TABLE SHOWS MEAN ( \pm SD) VALUES OF ALL THE DEPENDENT VARIABLES IN THE $0.25 \mathrm{HZ}$ AND $0.125 \mathrm{HZ}$ GAZE SHIFT CONDITIONS AND IN THE STATIONARY GAZE CONDITION. 
the stationary gaze condition in terms of postural control (Table 1). In summary, Table 1 shows that all participants exhibited more ample and/or faster COP, head, neck and lower back displacements (and therefore greater contributions of the bodyweight distribution and COP location mechanisms) in the two gaze shift conditions than in the stationary gaze condition.

\section{Complementary Analyses}

Asymmetry. There were no significant main effects of group or condition and no significant interaction effects for the rank of the mean ML COP position $\left(U_{s}>108.00, p>0.05 ; \chi^{2}=1.72\right.$, $p>0.05$ ), the rank of mean body marker positions (head position: $U_{s}>137.00, p>0.05 ; \chi^{2}=0.44, p>0.05$ ), the neck and lower back position $\left(F_{s}<0.88, \quad p>0.05\right)$ and the loading/unloading bodyweight distribution under each foot $\left(F_{s}<2.94, p>0.05\right)$.

In quiet stance. One-way ANOVAs for all dependent variables did not show any significant main effects of group in the stationary gaze condition $\left(F_{s}<3.70, p>0.05\right.$ and $U_{s}>114.00$, $p>0.05$ ). Hence, in the present study, the stationary gaze condition alone did not reveal any significant effects related to PD.

\section{DISCUSSION}

As expected, we observed significant, PD-related impairments in ML postural control coordination and mechanisms under active gaze shift conditions. When performing $80^{\circ} \mathrm{ML}$ gaze shifts, patients with PD turned their head less and turned their trunk more than healthy controls did. In fact, the patients displayed "en block" body coordination to a greater extent than the controls did. Moreover, the patients did not adjust the contributions of their ML postural control mechanisms at the hip and ankle to match the task's difficulty.

\section{A. Changes in Postural Control in the Visual Conditions}

The active gaze shift conditions challenged ML stance in both groups. Both groups of participants exhibited significantly more ample, faster neck and lower back displacements in the gaze shift conditions than in the stationary gaze condition (Fig. 3 ). In fact, displacement of the COP needed to be more ample and faster so that displacements of the body segments could be controlled under these conditions (cf. [17]). Indeed, displacement of COP (or displacement of the COM, to be more exact) controls displacement of the body, [33]) and it needs to be adjusted accordingly. One can hypothesize that greater contributions by the postural control mechanisms resulted in the higher COP displacements observed under gaze shift conditions (relative to quiet stance). Consistently, we found that the absolute amplitude contributions of each mechanism (SD COP $v$ and $\mathrm{SD} \mathrm{COP}_{c}$ ) and the active contribution of the COP location mechanism had a greater effect under gaze shift conditions than in quiet stance.

\section{B. Disease-Related Changes in Postural Coordination}

In the study by [19], patients with PD exhibited larger eye movements and smaller head movements when performing large, single gaze shifts $\left(45^{\circ}, 90^{\circ}, 135^{\circ}\right.$ and $\left.180^{\circ}\right)$. In the present study, patients with PD also showed less ample, slow angular movements of the head when performing moderately large $\left(80^{\circ}\right)$ gaze shifts. Relative to controls, the patients compensated for their lack of head angular movement by turning their trunk more. Although the patients were successful in the visual task (i.e. no failures and no obvious imbalance), more ample trunk angular movements may not constitute a safe postural strategy for performing visual tasks. In our present study and in the literature [1], [8], [9], patients with PD exhibited greater variability in ML lower back displacements than controls did (Fig. 3). The patients also exhibited faster ML lower back displacements than controls under gaze shift conditions. We found that the more difficult the visual task, the greater the difference in lower back mean velocity between patients and controls (Fig. 3). This is problematic for the patients' ML postural control. Indeed, the trunk is a heavy body segment and trunk movement can easily lead to postural instability. Patients with PD have smaller ML limits of stability than controls do [34]. Moreover, there is a strong relationship between ML instability and ML falls [13] and between ML falls and hip fracture [14].

Under the gaze shift conditions, patients with PD turned both their head and trunk by about the same angle, whereas controls turned their head $75 \%$ further than they did the trunk. Hence, the patients were probably less able than controls to dissociate movements of their upper and lower body segments, leading to "en block" behavior [35]. In a gait study, [36] reported that patients with PD were less able than controls to switch pelvicthoracic coordination from in-phase to anti-phase when the gait speed was increased. As observed in the literature [36], [37], we conclude that patients with PD cannot readily modulate their ML lower-upper body coordination. This lack of modulation may be due to elevated stiffness or axial rigidity of the trunk [21], [38]. In the following section, we discuss the impact of Parkinson's disease on the contributions of the ML postural control mechanisms.

\section{Disease-Related Changes in ML Postural Control Mechanisms}

Our additional analyses confirmed that patients with PD do not exhibit impairments in the ML bodyweight distribution and COP location mechanisms in quiet stance, as reported in the literature [17]. However, we detected a disease-related impairment in adapting the contribution of both mechanisms' contributions to suit the difficulty of the task performed. Indeed, the data in Fig. 4 show that while controls changed the contribution of their mechanisms when moving from passive to active visual tasks (as evidenced by the significant effect of the group $\mathrm{x}$ interaction), patients with PD did not. This finding has practical relevance because it may explain why patients with PD may well be stable in quiet stance but are less stable (and may fall more often) under conditions that challenge ML posture. One can hypothesize that during difficult ML tasks, the patients' ML postural control is inadequate and thus leads to greater ML instability. In a study of patients with PD, [12] reported that a lack of dissociation between the shoulder and the pelvis during axial rotation may be due to the inappropriate use of ground reaction forces. The bodyweight distribution 
mechanism $\left(\mathrm{COP}_{v}\right.$, cf. [15], [16]) also uses ground reaction forces and thus reveals a potential link between "en block" postural coordination and the lack of adaptive control at the trunk level.

\section{Conclusions and Perspectives}

Our study results showed that relative to healthy controls, patients with $\mathrm{PD}$ performed $\mathrm{ML} 80^{\circ}$ gaze shifts by turning their head less and thus turning their trunk more. These effects may be relevant to off-drug disease-related changes in motor coordination. The latter changes should be screened for in patients with PD, in order to detect and anticipate ML postural instability. Indeed, the motor coordination observed in the present study is unsafe because (i) the trunk is a heavy body segment and (ii) patients with PD have impairments in trunk movement and axial rotation [11], [12], [20]. We further showed that patients with PD were not able to adjust the contributions of their ML postural control mechanisms at the hip and ankle. Hence, our patients displayed a poor active ML postural control at an early stage in the disease (Hoehn \& Yahr stage 2) - even though none of the dependent postural control variables were related to clinical scores. In fact, disease-related changes in trunk coordination appear very early in the disease [9]; this is even the case for apparently healthy adults with an increased risk of Parkinson's disease [1], [39]. Our study results showed that patients with PD have clear signs of poor postural control as early as 4 years after disease onset.

In practical terms, patients with PD might achieve better ML postural control if they were to perform gaze shifts with more ample head-on-trunk angular movements. This coordination may reduce ML body sway and mitigate reliance on impaired ML postural control at the hip. The question then is whether this adaptation is possible in practice, since low-amplitude angular movement of the head may be due to poor use of proprioceptive information [40] and/or impairment of the basal ganglia's role in determining the body's orientation in space [12]. Further research should examine the effects of dopaminergic medications on these PD-related impairments in ML postural control and coordination of the head and trunk.

\section{ACKNOWLEDGMENT}

We thank Sébastien Szaffarczyk for guidance on use of the Simi Reality Motion System.

\section{REFERENCES}

[1] W. Maetzler, M. Mancini, I. Liepelt-Scarfone, K. C. Muller, C. Becker, R. C. van Lummel, E. Ainsworth, M. Hobert, J. Streffer, D. Berg, and L. Chiari, "Impaired trunk stability in individuals at high risk for Parkinson's disease," PloS ONE, vol. 7, e32240. doi:10.1371/journal.pone.0032240, Mar. 2012.

[2] A. Beuter, R. Hernandez, R. Rigal, J. Modolo, and P. J. Blanchet, "Postural sway and effect of levodopa in early Parkinson's disease," Can. J. Neurol. Sci., vol. 35, no. 1, pp. 65-68, Mar. 2008.

[3] N. Chastan, B. Debono, D. Maltête, and J. Weber, "Discordance between measured postural instability and absence of clinical symptoms in Parkinson's disease patients in the early stages of the disease," Movement Disord., vol. 23, no. 3, pp. 366-372, Feb 2008.

[4] S. L. Mitchell, J. J. Collins, C. J. De Luca, A. Burrows, and L. A. Lipsitz, "Open-loop and closed-loop postural control mechanisms in Parkinson's disease: Increased mediolateral activity during quiet standing," Neurosci. Lett., vol. 197, no. 2, pp. 133-136, Sept. 1995.
[5] L. Rocchi, L. Chiari, A. Cappello, and F. B. Horak, "Identification of distinct characteristics of postural sway in Parkinson's disease: A feature selection procedure based on principal component analysis," Neurosci. Lett., vol. 394, no. 2, pp. 140-145, Nov. 2006.

[6] M. K. Viitasalo, V. Kampman, K. A. Sotaniemi, S. Leppavuori, V. V. Myllyla, and J. T. Korpelainen, "Analysis of sway in Parkinson's disease using a new inclinometry-based method," Movement Disord., vol. 17, no. 4, pp. 663-669, Jul. 2002.

[7] J. W. Blaszczyk, R. Orawiee, and G. O. Duda-Klodowska, "Assessment of postural instability in patients with Parkinson's disease," Exp. Brain Res., vol. 183, no. 1, pp. 107-114, Oct. 2007.

[8] A. L. Adkin, B. R. Bloem, and J. H. J. Allum, "Trunk sway measurements during stance and gait tasks in Parkinson's disease," Gait Posture, vol. 22, no. 3, pp. 240-249, Nov. 2005.

[9] M. Mancini, F. B. Hora, G. Zampieri, P. Carlson-Kuhta, J. G. Nutt, and L. Chiari, "Trunk accelerometry reveals postural instability in untreated Parkinson's disease," Parkinsonism Relat. D., vol. 17, no. 7, pp. 557-562, June 2011.

[10] J. E. Visser, N. C. Voermans, L. B. Oude Nijhuuis, M. van der Eijk, R. Nijk, M. Munneke, and B. R. Bloem, "Quantification of trunk rotations during turning and walking in Parkinson's disease, "Clin. Neurophysiol., vol. 118, no. 7, pp. 1602-1606, Jul. 2007.

[11] F. B. Horak, D. Dimitrova, and J. G. Nutt, "Direction-specific postural instability in subjects with Parkinson's disease," Exp. Neurol., vol. 193, no. 2, pp. 504-521, June 2005.

[12] M. Vaugoyeau, F. Viallet, R. Aurenty, C. Assaiante, S. Mesure, and J. Massion, "Axial rotation in Parkinson's disease," J. Neurol., Neurosur. Ps., vol. 77, no. 7, pp. 815-821, Jul. 2006.

[13] B. E. Maki, P. J. Holliday, and A. K. A. Topper, "Prospective study of postural balance and risk of falling in an ambulatory and independent elderly population," J. Gerontol., vol. 49, no. 2, pp. M72-84, Mar 1994.

[14] M. W. Rogers, and M.-L. Mille, "Lateral Stability and Falls in Older People," Exercise Sport Sci. R., vol. 31, no. 4, pp. 182-187, Oct. 2003.

[15] D. A. Winter, F. Prince, P. Stergiou, and C. Powell, "Medial-lateral and anterior-posterior motor responses associated with center of pressure changes in quiet standing," Neurosci. Res. Commun., vol. 12, no. 3, pp. 141-148, Mar. 1993.

[16] D. A. Winter, F. Prince, J. S. Frank, C. Powell, and K. F. Zabjek, "Unified theory regarding $\mathrm{A} / \mathrm{P}$ and $\mathrm{M} / \mathrm{L}$ balance in quiet stance," J. neurophysiol., vol. 75, no. 6, pp. 2334-2343, June 1996.

[17] N. Termoz, S. E. Halliday, D. A. Winter, J. S. Frank, A. E. Patla, and F. Prince, "The control of upright stance in young, elderly and persons with Parkinson's disease," Gait posture, vol. 27, no. 3, pp. 463-470, Apr. 2008.

[18] C. T. Bonnet, and P. Despretz, "Large lateral head movements and postural control," Hum. Movement Sci., vol. 31, no. 6, pp. 1541-1551, Dec. 2012.

[19] D. Anastasopoulos, N. Ziavra, E. Savvidou, P. Bain, and A. M. Bronstein, "Altered eye-to-foot coordination in standing Parkinsonian patients during large gaze and whole-body reorientations," Movement Disord., vol. 26, no. 12, pp. 2201-2211, Oct. 2011.

[20] K. J. Bridgwater, and M. H. Sharpe, "Trunk muscle performance in early Parkinson's disease,” Phys. Ther., vol. 78, no. 6, pp. 566-576, June 1998.

[21] M. G. Carpenter, J. H. Allum, F. Honegger, A. L. Adkin, and B. R. Bloem, "Postural abnormalities to multidirectional stance perturbations in Parkinson's disease," J. Neurol., Neurosur. Ps., vol. 75, no. 9, pp. 12451254, Sept 2004.

[22] M. M. Hoehn, and M. D. Yahr, "Parkinsonism: Onset, progression, and mortality," Neurology, vol. 17, no. 5, pp. 427-442, May 1967.

[23] L. Rocchi, L. Chiari, and F. B. Horak, "Effects of deep brain stimulation and levodopa on postural sway in Parkinson's disease," J. Neurol., Neurosur. Ps., vol. 73, no. 2, pp. 267-274, Sept. 2002.

[24] M. F. Folstrein, S. E. Folstein, and P. R. McHugh, "Mini-mental state: A practical method for grading the cognitive state of patients for the clinician,” J. Psychiatr. Res., vol. 12, no. 2, pp. 189-198, Nov. 1975.

[25] A. J. Hughes, S. E. Daniel, L. Kilford, A. J. Lees, "Accuracy of clinical diagnosis of idiopathic Parkinson's disease: A clinic-pathological study of 100 cases. J. Neurol. Neurosurg. Ps., vol. 55, no. 3, pp. 181-184.

[26] B.-P. Bejjani, D. Gervais, I. Arnulf, S. Papadopoulos, S. Demeret, A.-M. Bonnet, P. Cornu, P. Damier, and Y.Agid, "Axial parkinsonian symptoms can be improved: The role of levodopa and bilateral subthalamic stimulation," J. Neurol., Neurosur. Ps., vol. 68, pp. 595-600, Dec. 2000.

[27] D. Dimitrova, F. B. Horak, and J. G. Nutt, "Postural muscle responses to multidirectional translations in patients with Parkinson's disease," $J$. Neurophysiol., vol. 91, no. 1, pp. 489-491, Aug. 2004. 
[28] W. E. McIlroy, and B. E. Maki, "Preferred placement of the feet during quiet stance: Development of a standardized foot placement for balance testing," Clin. Biomech., vol. 12, no. 1, pp. 66-70, Jan. 1997.

[29] P. R. Rougier, "Relative contribution of the pressure variations under the feet and body weight distribution over both legs in the control of upright stance," J. Biomech., vol. 40, no. 11, pp. 2477-2482, Feb. 2007.

[30] P. R. Rougier, "How spreading the forefeet apart influences upright standing control," Motor Control, vol. 12, no. 4, pp. 362-374, Oct. 2008.

[31] D. Lafond, H. Corriveau, and F. Prince, "Postural control mechanisms during quiet standing in patients with diabetic sensory neuropathy," Diabetes Care, vol. 27, no. 1, pp. 173-178, Jan. 2004.

[32] C. T. Bonnet, M. Mercier, and S. Szaffarczyk, "Impaired mediolateral postural control at the ankle in healthy, middle-aged adults," J. Motor Behav., vol. 45, no. 4, pp. 333-342, June 2013.

[33] D. A. Winter, "Human balance and postural control during standing and walking," Gait Posture, vol. 3, no. 4, pp. 193-214, Dec. 1995.

[34] E. E. van Wegen, R. E. van Emmerik, R. C. Wagenaar, and T. Ellis, "Stability boundaries and lateral postural control in Parkinson's disease," Motor Control, vol. 5, no. 2, pp. 254-269, Jul. 2001.

[35] I. Carpinella, P. Crenna, E. Calabrese, M. Rabuffeti, P. Mazzoleni, R. Nemni, and M. Ferrarin, "Locomotor function in the early stage of Parkinson's disease," IEEE T. Neural Syst. Rehabil. Eng., vol. 15, no. 4, pp. 543-551, Dec. 2007.

[36] R. E. A. van Emmerik, R. C. Wagenar, A. Winogrodzka, and E. C. Wolters, "Identification of axial rigidity during locomotion in Parkinson's disease," Arch. Phys. Med. Rehab., vol. 80, no. 2, pp. 186-191, Feb. 1999.

[37] W. G. Wright, V. S. Gurfinkel, J. Nutt, F. B. Horak, and P. J. Cordo, "Axial hypertonicity in Parkinson's disease: Direct measurements of trunk and hip torque," Exp. Neurol., vol. 208, no. 1, pp. 38-46, Nov. 2007.

[38] T. A. Boonstra, A. C. Schouten, and H.van der Kooij, "Identification of the contribution of the ankle and hip joints to multi-segmental balance control," J. NeuroEng. Rehabil., vol. 10, no. 23, http://.jneuroengrehab.com/content/10/1/23, Feb 2013.

[39] A. Mirelman, T. Gurevich, N. Giladi, A. Bar-Shira, A. Orr-Urtreger, and J. M. Hausdorff, "Gait alterations in healty carriers of the LRRK2 G2019S mutation," Ann. Neurol., vol. 69, no. 1, pp. 193-197, Jan. 2011.

[40] M., Tagliabue, G., Ferrigno, and F. B. Horak, "Effects of Parkinson's disease on proprioceptive control of posture and reaching while standing," Neuroscience, vol. 158, no. 4, pp. 1206-1214, Feb. 2009.

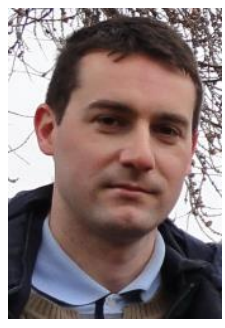

Cédrick T. Bonnet was born in Rabat Morocco, in 1978. He received the $\mathrm{Ph}$. D. degree in Kinesiology from the University of Minnesota, Minneapolis, in 2006.

From 2006 to 2008, he was a Postdoctorate fellow in the Center for the Ecological Study of Perception and Action, University of Connecticut, USA. From 2008 to 2009, he was Teaching and Research Assistant in the Faculté des sciences du sport, Aix-Marseille II. Since 2009, he has been a full time CNRS researcher in the Laboratoire de Neurosciences Fonctionnelles et Pathologies of Lille. He is the author of one book, of 20 articles, and more than 50 inventions. His research interests mostly include the interaction between postural control and visual behaviors.

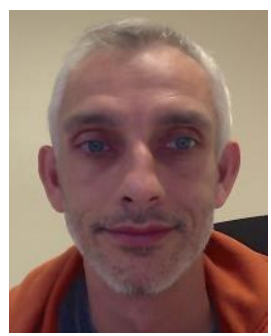

Arnaud Delval was born in 1974. He received the M.D. degree as a neurologist in 2004 and the $\mathrm{PhD}$ degree in neurosciences in 2007 from the University of Lille (France).

From 2004 to 2007, he was an assistant in the clinical neurophysiology department of Lille regional university hospital. He worked one year in 2008 at the Radboud University of Nijmegen Medical Centre (Netherlands) in the movement analysis unit with Bas Bloem. Since 2009, he has worked as a neurologist in the neurology and clinical neurophysiology departments of Lille Regional university hospital and is a lecturer in physiology at the medicine university of Lille since 2012.

His research interest includes interplays between cognition and locomotion, applied to the movement disorders. 